\title{
Intervention Project for a Significant Training in Distance Education
}

\author{
Andreza Regina Lopes da Silva ${ }^{1}$, Andreia de Bem Machado ${ }^{2}$, \\ Marcelo Ladislau da Silva ${ }^{3}$ \\ ${ }^{1,2,3}$ Universidade Federal de Santa Catarina
}

\begin{abstract}
Communication is a challenge nowadays, especially in the educational context be it in person or distance. This obstacle can be seen in the orientation process for intervention projects carried out in distance education. Therefore the purpose of this article is to present the contribution of the professor, in the course of postgraduate studies, offering an education of quality in distance learning. The methodology used is exploratory, descriptive from a case study. As a result it was observed that interaction and use of media, including social networks, contribute to enhance the training of the individual as a critical citizen in the knowledge society.
\end{abstract}

Keywords: Guidance. Training. Quality. Distance Education. Distance Learning.

\section{Introduction}

The methods of teaching-learning process in the current knowledge-based society are evidence of a conjugate of transformations related to different factors and levels of education, such as postgraduate programs, being them in person or distance. Distance education or distance learning, known in Brazil as EaD, is an educational mode where the relation of time and space lose their meaning. Driven by the need for continuing education, which comes from society, new educational practices are being used that rely on didactic teaching mediation in new formats, though innovative actions and use of technologies in new concepts of space - the so called cyberspace. As argued by Mallmann, De Bastos and Catapan (2010, p. 2) new spaces are constituted from the "use of internet and/or virtual environments mainly bringing concerns focused on distance mode" multiplying the forms of sociability between individuals.

Distance education has been using digital communication technologies to promote creative and innovative practices to promote teaching and learning as it allows texts, audio and video in the same interaction platform, for example. This practice allows the transposition of temporal and geographical barriers to learning, giving meaning to the teaching proposal. However, one can see that this form of pedagogical interaction is still considered a "new" practice both for teachers and students within educational institutions, which in turn do not present regulations and resolutions regarding the practice or the process. This reality demands from the professor a greater preparation so that academic activities may have quality in the final result of the guidance and training of the individual.

From these initial considerations, the goal of this article is: to present the contribution of the professor in the course of postgraduate studies, offering in distance education an education of quality. The methodology used to reach this goal is exploratory, descriptive from a case study. For that, four distinct sections were organized: introductory first, theoretical postulate in second, the third section describes the methodological guidance process from the reality here analyzed and finally the fourth section with final thoughts and suggestions for future work.

\section{Theoretical postulate}

Distance education, according to the Decree Law 5622, of December 2005, is an educational mode where distance student and teachers (time and space) through a didactic and pedagogical mediation, promote the process of teaching and learning through communication technologies (BRAZIL, 2005). In this sense, the concept of "distance" is directly related to time and space - that indirectly involves physical space and also psychological, social, cultural, economic aspects, among others - and not the act of "remote". Distance education does not mean studying alone. It does not mean distant education. For concepts and practices as interaction and interactivity are crucial.

Silva (2010) presents interactivity as an emergent phenomenon of contemporary society for being this a conscious practice of a more complex mode of communication at the same time paying attention to the existing interactions promoting them between user and technology either through "face-to-face" or "virtual" relationships. For Tori $(2010$, p. 28) interactive technologies contribute to [...] substantially minimize the effects of distance in learning. For this reason distance learning began to use intensely electronic technology as a means 
of approach, which fostered the emergence and evolution of communication tools, of authoring and management of courses, techniques and methods for creation, development and planning, as well as offering virtual learning activities.

Thus, it is considered that interactivity has a direct relationship with technologies and media, as interaction may or may not have this relationship, because it involves the exchange of two or more people faceto-face or on-line. In this case, the concepts "interaction" and "interactivity" must be understood distinctively. If related to the process of teaching and learning in distance education we can have moments of interaction without interactivity (human-human relation) or interactivity without interaction (human-machine).

Regardless of the level of training, interactive resources to promote interaction are essential in distance education. The second article of the Decree-Law 5622 points out that distance education may be offered in: basic education, in accordance with article 30 of this Decree; adult and youth education, in accordance with article 37 of Law \#9,394 of December 20, 1996; special education, in compliance with the relevant legal specificities; professional education, covering the following technical courses and mid-level and technological programs, top-level; higher education, covering the courses and programs: sequential; of graduation; of specialization; and masters; and doctorate.

In this educational modality postgraduate programs are growing considerably in recent years. According to EaD.BR 2014 Census, published in 2015, 53\% of the distribution of regulated distance education courses in Brazil is of postgraduate studies. Specialization, object of study reported in this article, a total $42 \%$ of the sample which gives us a number of 779 courses, in the general organization scenario of distance education which offers 1840 courses totally at distance (ABED, 2015).

Facing this scenario we can see the importance of the educator in the orientation process of completion of course working on graduation courses attended by the student. Interaction and interactivity contribute directly in this process and in the final result of orientation. And facing this discussion one can see that quality in guidance requires from the professor the utilization of various resources, synchronous or asynchronous - concepts, according to Tori (2010), related to the distance in time between transmitter and receiver where:

- Synchronous: communication between transmitter and receiver, here in this study represented by student and professor, in real time in which there is no significant time gap between emission and reception of the answer, for example, WhatsApp and social networks - when both are online -, pre-schedule chat, Skype.

- Asynchronous: when communication between transmitter and receiver takes place at different times, for example, forum, e-mail.

One can see that regardless of the form of communication, technologies contribute as interactive resources to promote the interactivity between professor and student enabling communication for the construction of knowledge through the organization of creative, cohesive and consistent ideas which requires in addition to digital communication technologies, monitoring with patience and discipline of both protagonists in this process.

The execution of the construction process of this scientific knowledge in a postgraduate program materializes with the completion of course work, which can be consolidated from different formats with different specificities defined from the course project. For example, monograph, research report, scientific paper or the creation of an intervention project which was used in the empirical analysis of this study.

- Monograph: scientific research on a specific theme, with methodological and scientific rigor, which the student writes at the end of the course of graduate or postgraduate.

- Research report: goal is to report the observation of a research data collection, without the data analysis phase.

- Scientific paper: a scientific text, with defined methods, resulting from a problem, produced to be published in specialized journals and evaluated by a community of researchers; the results of a research.

- Intervention project: consists in the elaboration of a plan to act in a reality in order to reform something that characterizes as problematic within the community in which one lives.

Thus, the intervention project, object of analysis in this article, is a scientific project which should design one or several actions to intervene in a reality to alleviate or eradicate a specific problem. In the practice of orientation focused on quality training the orientation is defined focusing on leading the student to prepare a project aimed at combining different actions organized from a goal to perform an action through a given context which will involve different artefacts and people.

Within this intention the goal of student and teacher must face the concepts and practices promoted from the conceptual intersection of the course and contextual reality identified by the student so that both are adherents to the proposed intervention. From this reflection the intervention project can be understood as an action research, because it is presented based on characteristic pillars of this research that brings as basic 
principle the dialectic and dynamic relationship between research and act, understanding that the research has as object the transformation of a given reality.

According to Thiollent (2008, p. 16) action research [...] is a kind of social research with empirical basis that is designed and carried out in close association with an action or with the resolution of a collective problem in which the researchers and participants representative of the situation or problem are involved in cooperative or participatory mode.

Thus, we can affirm that the development of an intervention project of sociological point of view approaches the action research that emphasizes, as Thiollent points out (2008), the analysis of different forms of action where these arise from a set of social relations structurally defined to intervention or action geared to problem solving effectively detected in a given context.

These different works of conclusion of course must follow beyond their objects, features of scientific language that express themselves from some key elements, namely: standard language respecting grammar rules, impartiality, objectivity, scientific basis, specialized vocabulary, grammar review, cohesion and coherence. To meet the goal of research and the main elements of this scientific writing is essential a direct communication between those involved, that is, professor and student.

For Kenski (2004, p. 55) digital technologies allow the construction of new forms of communication contributing to interactivity, such as through the virtual space structure from an online community where the main goal is in teaching-learning through ongoing dialogue to construct and reconstruct new knowledge.

In the interaction that occurs within the educational process of the guidance of intervention projects, carried out through technologies, we can highlight verbal communication demonstrated through writing and at times orally. These possibilities make different manifestation spaces and can be a dialogue between two or more people through features of a Virtual Environment of Teaching-Learning (Ambiente Virtal de EnsinoAprendizagem - AVEA in portuguese) among many other media educational resources that exist in the current knowledge society where technology and dissemination go hand in hand with knowledge in construction and reconstruction.

Right now resources are diverse and mediating technologies are extensive, we have social networks, emails, the AVEAs between software and applications that contribute to this process of interaction, such as, Skype and WhatsApp. Social networks in the educational context present strong feature for enhancing the communication process and can be mediated by e-mail (ZANCANARO et al. 2012).

The important thing in this communication is clear and effective mediation of the writing mode adopted by the course and the expected result, and for that the role of professor and student must be clear. Almeida (2011) shows that:

- the professor has the commitment to guide, by pre-scheduled appointment (face-to-face or virtual), either through informal communication that may be motivated by a possible doubt during the work process. The professor should recommend readings, lead the way and share ideas so that production might make both professor and student proud. However the professor is not the author of the work. The professor must ensure the quality and essential elements of a scientific project where goals, theoretical foundation and results are well aligned.

- the student is committed to carry out the project that starts with the identification of the reality to be intervene and is consolidated with the delivery of the final writing project that includes the set of actions for intervention generating analysis and description of results. In this case it is up to the student the commitment with the intervention but mainly with regular communication with the professor, because from there is the interaction for the continued improvement of work in construction and subsequent training.

In this sense we can say that the orientation process is a two-way process where professor and student need to communicate orally, in writing, in person or at distance. The resource, time and space have no direct relation with the quality of this process that is constantly improving, but interaction and interactivity promoted throughout this construction are key elements for quality training and so is considered that to promote quality training for teachers is one of the main paths to a quality education, regardless of the educational mode.

The intervention project is an innovative methodology of scientific and social point of view. It is expected from both protagonists of the process (professor and student, in this study) to build their relationship on solid bases and to answer the questions: "How can research overcome the proposition of a simple "idea" and innovate to improve? This challenge must be flexible, knowing the multiplicity of paths to be defined from the different circumstances that present themselves along the way (THIOLLENT, 2008).

\section{Guidance methodology}

The case study presented in this paper reports a guidance model for the development of an intervention project in a specialization course, lasting 510 hours, including 60 hours for the preparation of the course conclusion working, offered in partnership from two federal public institutions, to meet and train public safety 
officers. The partnership was seen as relevant for understanding that technical knowledge belonged to one of the partners and knowledge for academic-pedagogical implementation and management of the course, in contrast to a financial budget proposed, belonged to the other institution involved.

The course began in 2010, within the Programa Nacional de Formação em Administração Pública (PNAP), linked to the Universidade Aberta do Brasil (UAB), with a master class in the South of Santa Catarina. The first orientation, resulting from the first offering of the course, happened through presentation via AVEA resource, with the support of the mentoring team, as well as the course coordination and the monograph. With this experience, was realized the need to expand communication through interactivity and increase interaction between professors and students in order to improve the quality of the training process. With the awareness that the evaluation is not merely quantitative as the student learning mode is quantitative, but qualitatively in the action of teaching.

It is observed that in the process of orientation in distance education the interaction between professor and student is primordial, establishing clear guidelines to students about concepts that they intend to research, the student should clearly show interest in the research theme and have access to information. For that, technological artefacts were identified as improvers in the process for construction of knowledge. The main resources used were:

- AVEA: This environment was organized from the resources of moodle where different phases of project construction were posted. The exchange of formal communication and methodological guidelines demanded by the course were also made exclusively for this communication that occurred throughout the course in an asynchronous and interactive way.

- Skype: This resource allows guidelines meeting synchronously and with interaction between student and professor.

- WhatsApp: used for quick questions this resource was heavily used in the communication.

- Social media: Facebook was the most used media and generally it was a student's initiative in order to promote with the professor a synchronous communication when both were online and new questions and suggestions needed to be shared.

Phone calls and e-mails were used eventually. Both features were required usually because of technological deficiency of one of the members. All media resources were used to promote interactivity and/or interaction in the process of guidance where the role of the professor, from the course in question, became effective from: references, methodological procedures; and stimulate research.

Another important factor that contributes to a quality relationship assesses the knowledge of the professor regarding the research area chosen by the student, in addition to availability and interest to accompany this student that takes an intense role in distance education that is mediated and enhanced with the use of technology often requiring from the professor more organization and planning. It is a relationship that to be established must count with empathy between professor and student.

So, it is clear in the orientation process in distance education that the need for quality training is directly related to interactive and interaction processes to promote effective communication, whether synchronous or asynchronous, which takes place in a continuous and non-linear way constituting a construction network, as shown in the following figure.

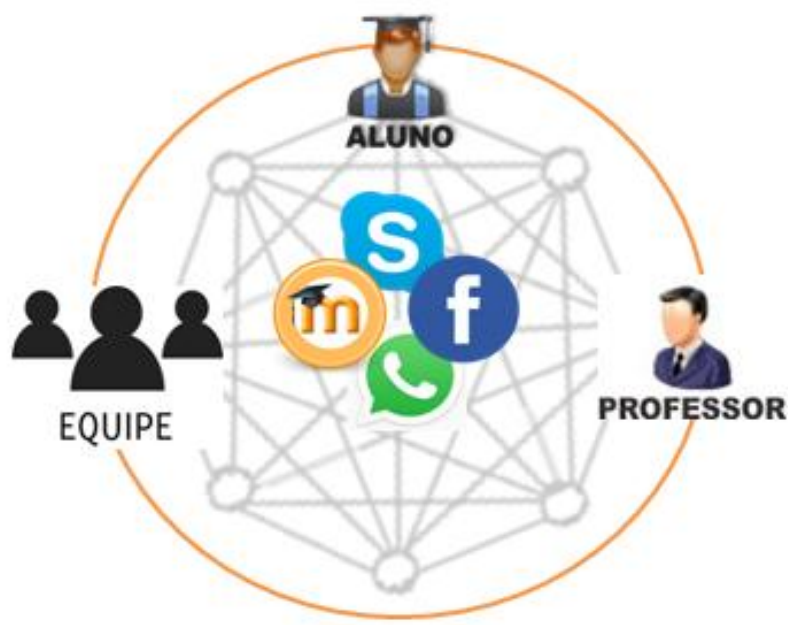

Figure 1 - Process of orientation in distance education

Source: Prepared by the authors (2016). 
The important thing is to use the different digital communication resources to promote a quick and effective response, so the student will not fell discouraged and give up. Always valuing differences, stimulating new ideas, opinions and attitudes, in order to promote the ability to learn to think and learn to learn. So that the expected result may be reached the professor will not work isolated, a mentoring team and course coordination are present to assist them. Another determining factor of success was the set maximum number of students: five; In case the professor was not assisting other students of other courses, or other institutions.

In this sense, the professor must be a facilitator who leads the student in their learning process, resulting from the construction of knowledge. When this relationship is grounded, the student enjoys a sense of security, element identified as essential in the intervention projects of good quality. The student needs to feel welcome and it has been identified that this feeling intensifies in the orientation process in distance education. This welcoming feeling has been identified in two key moments: reply to questions sent through different medias and also the constructive and formative feedback, not merely an evaluation conducted during the activities proposed to design the final project.

The professor in this guidance process should help the student to choose the research topic, as well as follow up all the academic research and writing of it. The student should interact with the professor through debates, search for information, reference research and/or field research and also an engagement with the research topic that will allow for the student to succeed in the final product of the course, which is in this case the intervention project.

Thus, the professor and the student should have a relationship of mutual trust, i.e., it is the professor who will direct the student on a trail often formed by unknown obstacles. The professor should not expect the students to be submissive, nor their consent with everything the professor says or does, but their respect, their affection and their seriousness. In the construction of this commitment factors were identified in the guidance process in the construction of the intervention project, a postgraduate program, which contributed to quality training. To assist in this process it was found that the use of media and convergence of the same through different technologies are key.

\section{Final considerations}

It is up to the professor to communicate and not just correct the student. On the contrary it is believed that it is necessary to promote self-correction, because the current society requires from the individual to understand and develop the objectives from a given context. So, it is up to the professor, in a quality training process, to choose the best way to promote interaction having as main goal the propulsion of the individual as protagonist of this process seeking to improve their learning. Guide to quality is no simple task. Contribute to the construction of new knowledge and ordering ideas creatively, cohesively and consistently requires patience and skills that should be developed on a daily basis from the need of each individual.

In this study, which presents the process of guidance in the preparation of an intervention project, we identified that the use of digital communication technologies, social networks, virtual teaching and learning environment, Skype and WhatsApp contributed potentially to the commitment with quality training in distance education. This situation allows inferring that the extension and integration of the use of media in the process of orientation was a motivation factor, adding value to the training of students. And it can also be inferred that facing the trend and growth of postgraduate courses, there is the need for research and report practices to work the orientation process in distance education so that the student has quality training.

\section{References}

[1]. ABED. Census DE.BR: relatório analítico da aprendizagem a distância no Brasil, 2014. Curitiba: Ibpex, 2015.

[2]. ALMEIDA, M. de S. Elaboração de projeto, TCC, dissertação e tese: uma abordagem simples, prática e objetiva. Sao Paulo: Atlas, 2011.

[3]. KENSKI, V. M. Tecnologias e ensino presencial e a distância. Campinas, SP: Papirus, 2004

[4]. MALlMANN, E. M.; DE BASTOS, F. da P. ; CATAPAN, A. H. Desafios da Mediação Pedagógica em Cursos de Formação de Professores Presenciais e a Distância. Revista Educação, UFSM, v. 31, p. 367-382, 2006.

[5]. SILVA, M. Sala de Aula Interativa. Rio de Janeiro: Quartel Editora \& Comunicação Ltda. 2000

[6]. THIOLLENT, M. Metodologia da pesquisa-ação. Sao Paulo: Cortez, 2008.

[7]. TORI, R. Educação sem distância: as tecnologias interativas na redução de distâncias em ensino e aprendizagem. Sao Paulo: Senac SP, 2010.

[8]. ZANCANARO, A. et al. Redes Sociais na Educação a Distância: uma análise do projeto e-Nova. DataGramaZero - Revista de Informação, v. 13, n. 2, April., 2012. 